\title{
Condicionamento Agrometeorológico em Cultivares de Alface
}

\author{
Gabriel Siqueira Tavares Fernandes ${ }^{1}$ (D), Edivania de Araujo Lima ${ }^{2}$ (D), Adriana Ursulino Alves ${ }^{2}$, \\ Victor Alves Brito ${ }^{2}$, Lucas Carvalho Soares ${ }^{2}$ \\ ${ }^{1}$ Departamento de Engenharia Agricola, Universidade Federal Rural de Pernambuco, \\ Recife, PE, Brasil. \\ ${ }^{2}$ Departamento de Engenharia Agronômica, Universidade Federal do Piauí, \\ Bom Jesus, PI, Brasil.
}

Recebido em: 26 de Julho de 2018 - Aceito em: 23 de Março de 2019

\begin{abstract}
Resumo
Objetivou-se avaliar a adaptação de cultivares de alface com base na metodologia dos graus-dia, em estufa, no vale do Gurguéia. O experimento foi conduzido em ambiente protegido, na Universidade Federal do Piauí - UFPI/CPCE. O delineamento adotado foi em blocos ao acaso, sendo os tratamentos cultivares de alface. As cultivares utilizadas foram: Simpson, Bruna, Palmas e Grand Rapids - TBR. Os dados meteorológicos (temperatura do ar, umidade relativa, pressão atmosférica, velocidade dos ventos e precipitação) foram obtidos em uma estação meteorológica portátil que foi instalada no ambiente protegido. A temperatura do ar durante o experimento apresentou máxima de $33{ }^{\circ} \mathrm{C}$ e mínima de $26^{\circ} \mathrm{C}$. As cultivares 'Simpson' e 'Grand Rapids' apresentaram um ciclo mais precoce ( 45 dias), quando comparada às demais (52 dias), ambas com constante térmica (CT) de $898^{\circ} \mathrm{gd}$. As cultivares 'Bruna' e 'Palmas' apresentaram $\mathrm{CT}=1050^{\circ} \mathrm{gd}$. Dentre as cultivares avaliadas, as cultivares 'Palmas' e 'Bruna' obtiveram comportamento e morfologia adequados em relação às altas temperaturas regionais. Dessa forma, conclui-se que as cultivares 'Palmas' e 'Bruna' possuem potencial produtivo para a região, quando cultivada em ambiente protegido.
\end{abstract}

Palavras-chave: produção vegetal, Lactuca sativa, fenologia, graus-dia.

\section{Agrometeorological Conditioning in Lettuce Cultivars}

\begin{abstract}
The objective of this study was to evaluate the adaptation of lettuce cultivars based on day-degree greenhouse methods in the Gurguéia Valley. The experiment was carried out in a protected environment, at the Federal University of Piauí UFPI / CPCE. The experimental design was a randomized block design, with treatments of lettuce cultivars. The cultivars used were: Simpson, Bruna, Palmas and Grand Rapids - TBR. The meteorological data (air temperature, relative humidity, atmospheric pressure, wind velocity and precipitation) were obtained in a portable weather station that was installed in the protected environment. The temperature of the air during the experiment presented maximum of $33^{\circ} \mathrm{C}$ and minimum of $26^{\circ} \mathrm{C}$. The cultivars 'Simpson' and 'Grand Rapids' presented an earlier cycle ( 45 days), when compared to the others (52 days), both with a thermal constant (CT) of $898^{\circ} \mathrm{gd}$. The cultivars 'Bruna' and 'Palmas' showed $\mathrm{CT}=1050{ }^{\circ} \mathrm{gd}$. Among the evaluated cultivars, the 'Palmas' and 'Bruna' cultivars obtained adequate behavior and morphology in relation to the high regional temperatures. Thus, it is concluded that the 'Palmas' and 'Bruna' cultivars have productive potential for the region when cultivated in a protected environment.
\end{abstract}

Keywords: vegetables production, Lactuca sativa, phenology, degree-days.

\section{Introdução}

A alface (Lactuca sativa L.) é cultivada em todas as regiões brasileiras, sendo a preferência de consumo na forma de salada. Sua aceitação se deve ao sabor agradável, qualidade nutricional, fácil preparo e preço atrativo para o consumidor. No Brasil, existe uma grande diversidade de

Autor de correspondência: Gabriel Siqueira Tavares Fernandes, agrogabrielt@gmail.com. 
cultivares de alface disponíveis (Suinaga et al., 2013) e os principais tipos de alface cultivados em ordem de importância econômica são a crespa, a americana, a lisa e a romana (Sala e Costa, 2012). Em sua composição podemse encontrar vitaminas A, B1, B2 e C, além de sais de cálcio e ferro (Sousa et al., 2007).

Os brasileiros estão apresentando hábitos alimentares mais saudáveis a cada dia. Em virtude desta constatação, avalia-se que o consumo de hortaliças folhosas também tem aumentado no País. Contudo, a produção e a qualidade dessas olerícolas oscilam bastante, porque são muito dependentes das condições climáticas. Lactuca sativa é a hortaliça folhosa mais importante economicamente para o Brasil, a qual é cultivada em praticamente todas as regiões do país. Em decorrência da modernização da agricultura, tornou-se mais fácil sua produção nas diversas regiões. No entanto, ainda persistem fortes limitações (Carvalho Filho et al., 2009).

Os elementos meteorológicos podem afetar de forma favorável ou desfavorável a produção de hortaliças, observa-se que temperaturas elevadas (superiores a $24{ }^{\circ} \mathrm{C}$ ) associadas à alta pluviosidade podem levar o alfacicultor a perdas de até $60 \%$ em decorrência da maior umidade relativa (Vargas et al, 2015). No entanto, a temperatura do ar é o responsável pela definição da produção de alface e, uma forma de relacionar o seu desenvolvimento com esse elemento é o uso do sistema de unidades térmicas ou grausdia (Brunini, 1976). Neste método de análise considera-se uma temperatura mínima abaixo da qual o vegetal paralisa o seu desenvolvimento (temperatura-base inferior), sendo o graus-dia definido como "a quantidade de calor efetivamente acumulada durante o dia e favorável ao crescimento do vegetal" (Pereira et al., 2002).

Dessa forma, a caracterização de suas exigências térmicas, tanto total quanto para cada fase fenológica, é crucial para a previsão da duração do ciclo da cultura em função do ambiente. Essas informações, associadas ao conhecimento da fenologia da cultura, podem ser utilizadas no planejamento para a definição da época de semeadura, da utilização de insumos e da época de colheita. Outra aplicação da metodologia de graus-dia, pode ser a identificação de variedades cultivadas com diferentes exigências térmicas em programas de melhoramento, visando o mercado consumidor (Schafer, 2009).

Diante do exposto, a execução do presente estudo teve por objetivo, avaliar a adaptação de cultivares de alface com base na metodologia dos graus-dia, em estufa, no vale do Gurguéia.

$$
\text { Xmed }=\frac{X_{00: 00}+X_{03: 00}+X_{06: 00}+X_{09: 00}+X_{12: 00}+X_{15: 00}+X_{18: 00}+X_{21: 00}}{9}
$$

\section{Material e Métodos}

$\mathrm{O}$ experimento foi conduzido em ambiente protegido (telado) utilizando sombrite com malha de $50 \%$ de sombreamento, na Universidade Federal do Piauí (UFPI), Campus Professora Cinobelina Elvas, em Bom Jesus - PI, entre os meses de março e abril de 2017. O município integra a região do Semiárido Piauiense, possuindo clima quente e úmido, classificado por Köppen como Awa (Tropical chuvoso com estação seca no inverno e temperatura média do mês mais quente superior a $22{ }^{\circ} \mathrm{C}$ ). Localizado nas coordenadas geográficas $09^{\circ} 04^{\prime} 28^{\prime \prime} \mathrm{S}, 4^{\circ} 21^{\prime} 31^{\prime \prime} \mathrm{W}$, e altitude média de $277 \mathrm{~m}$, com precipitação média entre 900 a $1200 \mathrm{~mm}$ ano ${ }^{-1}$ e temperatura média de $26,2{ }^{\circ} \mathrm{C}$ (Inmet, 2017).

Os tratamentos utilizados foram as cultivares de alface 'Simpson', 'Bruna', 'Palmas' e 'Grand Rapids TBR', todas classificadas como alface tipo crespa. O delineamento adotado foi em blocos ao acaso, sendo os tratamentos cultivares de alface (Lactuca sativa), com dez blocos e uma planta como unidade experimental, totalizando quarenta plantas.

As sementes de alface foram semeadas em bandejas de poliestireno expandido (128 células), preenchidas com substrato comercial Balsaplant ${ }^{\circledR}$, utilizando quatro sementes por célula, no dia 02/03/2017. As mudas foram irrigadas duas vezes ao dia. $\mathrm{O}$ transplante foi realizado quando as mudas apresentaram de quatro a seis folhas definitivas.

$\mathrm{O}$ solo foi acondicionado em recipientes plásticos com capacidade para $8 \mathrm{~L}$, sendo preenchidos com 7,5 kg de solo, o mesmo foi um Latossolo Amarelo Distrófico coletado nas proximidades da Universidade Federal do Piauí. Os vasos foram organizados num espaçamento entre fileiras de $0,35 \mathrm{~m}$ e entre plantas de $0,35 \mathrm{~m}$. A calagem foi realizada de forma a elevar a saturação de bases a $70 \%$ (Filgueira, 2008) e a adubação a ser utilizada foi aplicada conforme a análise química do solo (Tabela 1). As plantas foram irrigadas três vezes ao dia, aplicando $250 \mathrm{~mL}$ de água.

Os dados meteorológicos foram obtidos em uma estação meteorológica portátil (modelo Aw001) que foi instalada no interior do ambiente protegido, as variáveis meteorológicas que foram monitorados são: temperatura do ar $\left({ }^{\circ} \mathrm{C}\right)$, umidade relativa do ar $(\%)$, pressão atmosférica $(\mathrm{hPa})$, velocidade dos ventos $(\mathrm{m} / \mathrm{s})$ e precipitação $(\mathrm{mm})$. Todas as variáveis meteorológicas foram coletadas a cada três horas e procedeu-se cálculo média diária.

em que: $X$ é a variável meteorológica. 
Tabela 1 - Caracterização físico-química do solo utilizado no experimento, Bom Jesus, PI, Brasil, 2017.

\begin{tabular}{|c|c|c|c|c|}
\hline $\mathrm{pH}\left(\mathrm{H}_{2} \mathrm{O}\right)$ & $\mathrm{H}+\mathrm{Al}\left(\mathrm{cmol}_{\mathrm{c}} \mathrm{dm}^{-3}\right)$ & $\mathrm{Al}\left(\mathrm{cmol}_{\mathrm{c}} \mathrm{dm}^{-3}\right)$ & $\mathrm{Ca}\left(\mathrm{cmol}_{\mathrm{c}} \mathrm{dm}^{-3}\right)$ & $\mathrm{Mg}\left(\mathrm{cmol}_{\mathrm{c}} \mathrm{dm}^{-3}\right.$ \\
\hline 5,5 & 2,64 & 0 & 1,22 & 0,24 \\
\hline $\mathrm{Fe}\left(\mathrm{mg} \mathrm{dm}^{-3}\right)$ & $\mathrm{Cu}\left(\mathrm{mg} \mathrm{dm}^{-3}\right)$ & $\operatorname{Mn}\left(\mathrm{mg} \mathrm{dm}^{-3}\right)$ & $\mathrm{Zn}\left(\mathrm{mg} \mathrm{dm}^{-3}\right)$ & V (\%) \\
\hline 77,47 & 0,14 & 5,09 & 1,11 & 37,3 \\
\hline $\mathrm{K}\left(\mathrm{cmol}_{\mathrm{c}} \mathrm{dm}^{-3}\right)$ & $\mathrm{SB}\left(\mathrm{cmol}_{\mathrm{c}} \mathrm{dm}^{-3}\right)$ & $\mathrm{T}\left(\mathrm{cmol}_{\mathrm{c}} \mathrm{dm}^{-3}\right)$ & \multicolumn{2}{|c|}{$\mathrm{P}\left(\mathrm{mg} \mathrm{dm}^{-3}\right)$} \\
\hline 0,12 & 1,57 & 4,21 & \multicolumn{2}{|c|}{49,13} \\
\hline $\mathrm{m}(\%)$ & M.O. $\left(\mathrm{g} \mathrm{kg}^{-1}\right)$ & Areia (\%) & Argila (\%) & Silte $(\%)$ \\
\hline 0 & 13,6 & 77,2 & 20,6 & 22 \\
\hline
\end{tabular}

$\mathrm{pH}=$ potencial de hidrogeniônico; $(\mathrm{H}+\mathrm{Al})$ Acidez potencial; $\mathrm{Al}=$ Alumínio; $\mathrm{Ca}=\mathrm{Cálcio} ; \mathrm{Mg}=$ Magnésio; $\mathrm{K}=$ Potássio, $\mathrm{SB}=\mathrm{Soma}$ de Bases Trocáveis; (T) - Capacidade de Troca Catiônica a pH 7,0; P = Fósforo; $\mathrm{Fe}=$ Ferro; $\mathrm{Cu}=$ Cobre; $\mathrm{Mn}=$ Manganês; $\mathrm{Zn}=\mathrm{Zinco}$; V = Índice de Saturação de Bases e $\mathrm{m}=$ Índice de Saturação de Alumínio.

A capacidade térmica utilizada para o desenvolvimento das cultivares de alface foi calculada com base na metodologia de graus-dia, através da Eq. (2) (Pereira et al., 2002), que consiste na soma térmica diária da cultura, finalizando com o somatório geral, resultando na necessidade térmica dessa. A temperatura basal mínima utilizada foi de $8{ }^{\circ} \mathrm{C}$ para o período correspondente à semeaduratransplantio e $10{ }^{\circ} \mathrm{C}$ para transplantio-colheita (Brunini et al., 1976).

$$
G D=\sum_{i=1}^{n}\left(\frac{T_{\max }+T_{\min }}{2}-T_{b}\right)
$$

em que $G D$ é o total de graus-dia acumulado; $T_{\max }$ é a temperatura do ar máxima diária $\left({ }^{\circ} \mathrm{C}\right) ; T_{\min }$ é a temperatura do ar mínima diária $(\mathrm{C}) ; T_{b}$ é a temperatura-base inferior $\left({ }^{\circ} \mathrm{C}\right)$; n é o número de dias do período analisado.

Durante o ciclo da cultura foram avaliadas, semanalmente, após o transplantio, as variáveis vegetativas: Número de folhas por planta: contagem das folhas verdes; altura de plantas: medida da base do caule até a parte apical da planta, com régua graduada; diâmetro da roseta: medido com auxílio de uma régua graduada, a partir de cada extremidade da planta.

A avaliação final consistiu na quantificação de variáveis de crescimento vegetal, sendo elas: Diâmetro do colo: medido com paquímetro digital Digimess ${ }^{\circledR}$ graduado em milímetros; Diâmetro da roseta; Altura de plantas: medida da base do caule até a região superior; Número de folhas: contagem de folhas verdes; Massa fresca da parte aérea: quantificada através de balança analítica eletrônica $(0,001$ g); Massa seca da parte aérea: Obtida através da secagem em estufa por $72 \mathrm{~h}$, à $65^{\circ} \mathrm{C}$ e quantificada com balança analítica eletrônica $(0,001 \mathrm{~g})$.

A colheita foi realizada quando $50 \%$ das plantas de cada tratamento atingiram o diâmetro da roseta de $25 \mathrm{~cm}$ (diâmetro comercial), sendo esse ponto, o fim do acúmulo térmico que pretendeu-se avaliar.

Posteriormente, os dados obtidos foram analisados por meio da análise de variância utilizando o teste $\mathrm{F}$ a $5 \%$ de probabilidade. Para as variáveis significativas, realizouse a comparação de médias pelo teste de Tukey ao nível de $5 \%$ probabilidade utilizando o sistema computacional $\mathrm{R}$ (2014). As variáveis meteorológicas e fitotécnicas foram relacionadas a partir de análise de regressão utilizando o software SigmaPlot (2008) e, foram consideradas apenas as que apresentaram nível de significância $(p \leq 0,05)$ pelo teste de F.

\section{Resultados e Discussão}

A temperatura média diária do ar durante o experimento apresentou máxima de $33{ }^{\circ} \mathrm{C}$ e mínima de $26{ }^{\circ} \mathrm{C}$, com amplitude térmica de $7^{\circ} \mathrm{C}$ entre os períodos diurno e noturno. Os maiores registros desse elemento foram registrados no horário das 21:00 h.

As temperaturas registradas no período diário (dados coletados às 06:00, 09:00, 12:00 e 15:00), apresentaram um padrão de variação temporal, mostrando conexão entre os horários e pouca variação entre os mesmos (Fig. 1). Os menores valores observados situaram-se no horário das 12:00, em que registrou-se temperaturas em torno de $22{ }^{\circ} \mathrm{C}$.

No período noturno (dados coletados às 18:00, 21:00, 00:00 e 03:00), foi possível registrar um padrão mais acentuado na variação horária, com baixa amplitude térmica entre os horários (Fig. 2). Os menores valores para o elemento foram encontrados às 03:00 e os maiores às 21:00, apresentando, em contrapartida, um pico em torno de $19^{\circ} \mathrm{C}$ nesse horário.

Diante do padrão de comportamento da temperatura do ar nos dois períodos, pode-se afirmar que a variação horária do mesmo é maior durante o dia, apresentando, em contrapartida, um valor médio de $28,6{ }^{\circ} \mathrm{C}$, sendo inferior ao noturno $\left(30,2{ }^{\circ} \mathrm{C}\right)$. Esse fato pode-se explicar porque apesar de o período diurno está sobre influência da radiação solar, trata-se de um ambiente protegido, o que modifica toda a dinâmica térmica e circulação dos ventos, gerando um comportamento diferente do que é normalmente observado em condições ambientes abertos. 


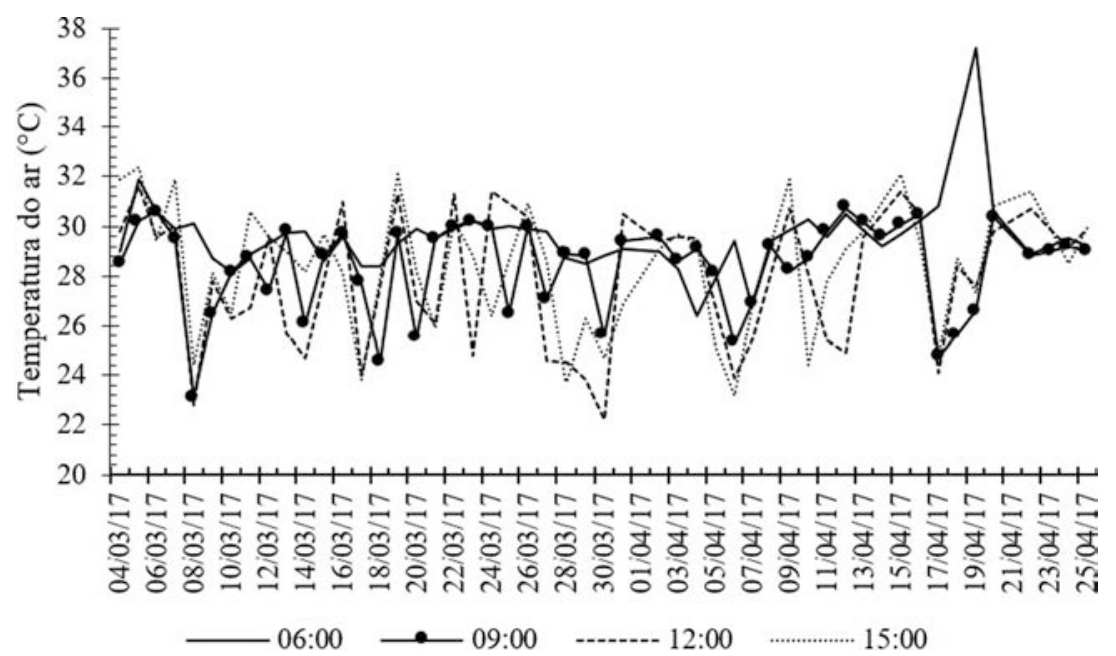

Figura 1 - Evolução da temperatura do ar diurna, no período de 04/03/2017 a 25/04/2017, na região de Bom Jesus - PI.

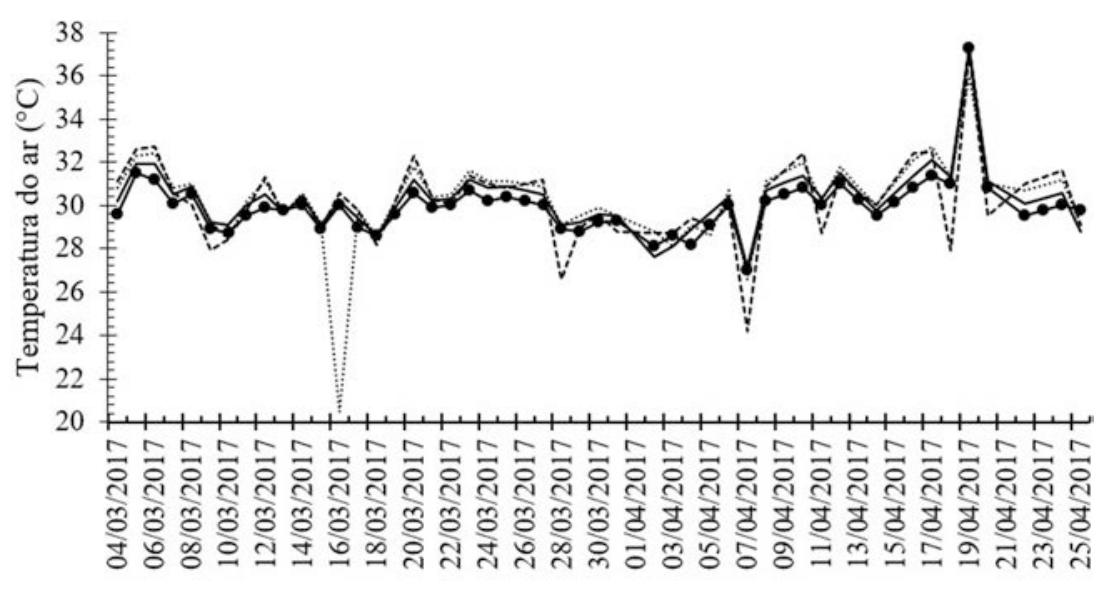

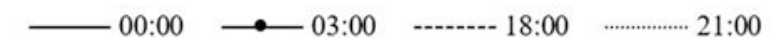

Figura 2 - Evolução da temperatura do ar noturna, no período de 04/03/2017 a 25/04/2017, na região de Bom Jesus - PI.

Salienta-se que a situação mencionada é verídica, pois obteve-se uma maior circulação de ventos no período diário, sendo a ação desse elemento climático registrada durante o dia em $43 \%$ do período experimental, variando de 0,3 a $0,7 \mathrm{~m} / \mathrm{s}$. Durante a noite, registrou-se em $4 \%$, com a o mesmo padrão de variação.

Quanto à umidade relativa do ar média diária, registrou-se, uma mínima de $40 \%$, máxima de $61 \%$, média de $50,5 \%$ e amplitude de $0,06 \%$ entre os períodos diurno e noturno.

No período diário (Fig. 3), nota-se uma variação acentuada do elemento climático no decorrer do dia, os maiores valores registrados foram configurados no horário das 06:00 e os menores no horário das 15:00 com picos em torno de 30\% às 12:00.

Durante a noite, é possível observar uma maior uniformidade da distribuição horária da umidade relativa do ar (Fig. 4). No entanto, têm-se maiores valores no horário das 03:00 e menores às 18:00 com pico em torno de 35\% às 21:00.
A partir da observação de dados médios diários da temperatura do ar e umidade relativa (Fig. 5) é possível verificar um padrão de relação inversamente proporcional entre a temperatura e umidade relativa do ar. Comportamento adequado e já esperado devido suas propriedades físicas.

A adaptação das cultivares de alface nas condições meteorológicas da região estudada foi dificultada, podendo ter seu desenvolvimento comprometido e expressão inadequada do seu potencial produtivo (Silva et al., 2000), pois, os valores de temperatura registrados no período experimental foram superiores à faixa de cultivo ótimo para as mesmas (Fig. 1), que situa-se entre 15 a $18{ }^{\circ} \mathrm{C}$ (Brunini et al., 1976), tolerando ainda, temperaturas de $30{ }^{\circ} \mathrm{C}$ (Duarte et al., 1992). Em contrapartida, vale ressaltar que $80 \%$ dos registros de temperatura situaram-se dentro ou próximo ao limite tolerável pelas cultivares utilizadas.

Adicionalmente, os valores registrados de umidade relativa no período experimental (40 a $61 \%$ ), foram 


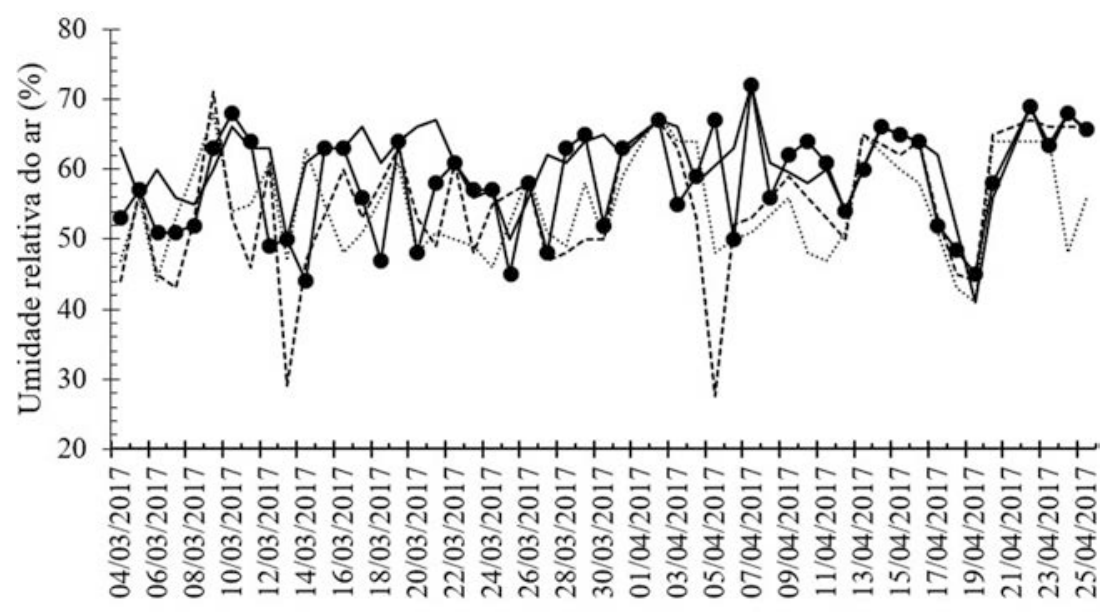

06:00 — 09:00

$12: 00$

15:00

Figura 3 - Evolução da umidade relativa do ar diária, no período de 04/03/2017 a 25/04/2017, na região de Bom Jesus - PI.
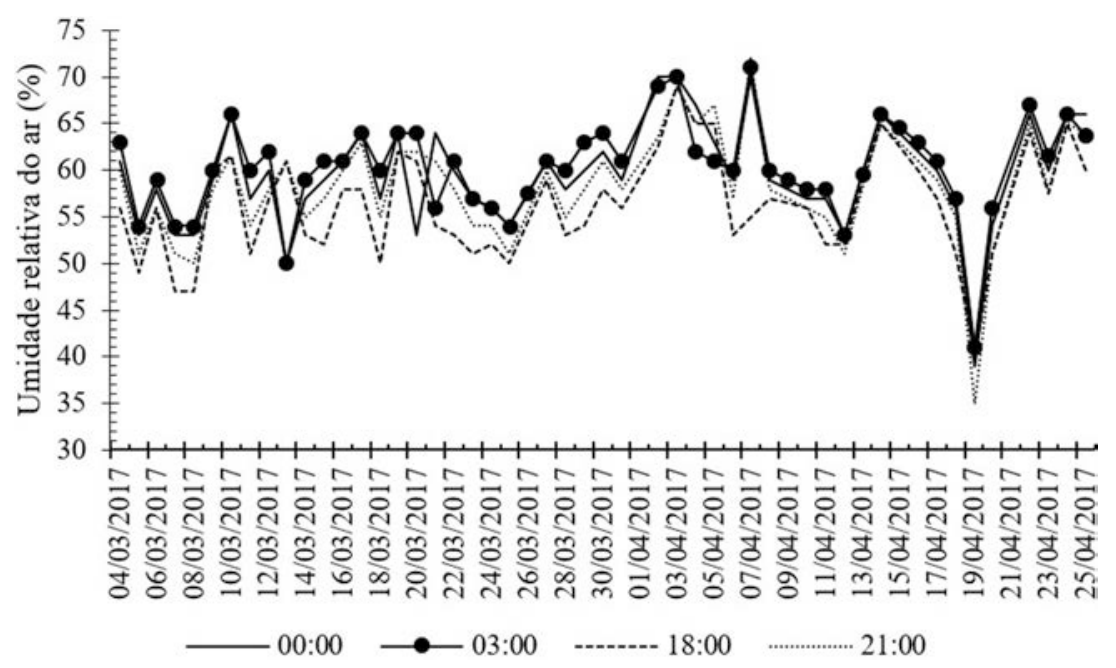

Figura 4 - Evolução da umidade relativa do ar noturna, no período de 04/03/2017 a 25/04/2017, na região de Bom Jesus - PI.

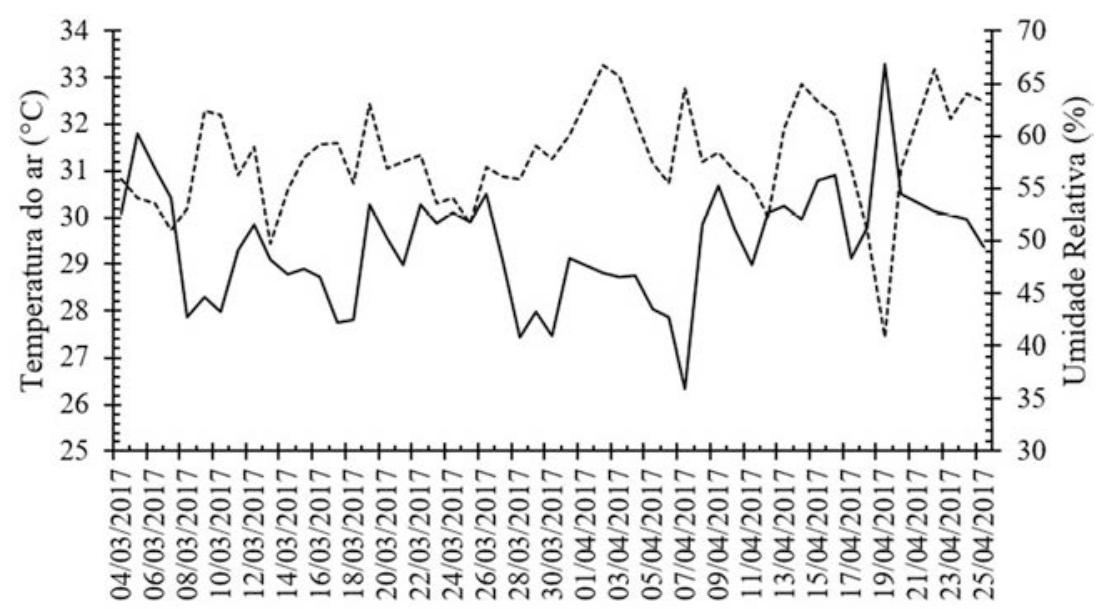

- Temperatura do ar $\left({ }^{\circ} \mathrm{C}\right) \quad$-.----- Umidade Relativa $(\%)$

Figura 5 - Relação entre médias diárias de temperatura do ar e umidade relativa, no período de 04/03/2017 a 25/04/2017, na região de Bom Jesus - PI. 
majoritariamente inferiores aos valores recomendados como ótimos para a cultura da alface, sendo estes variando de 60 e $80 \%$ (Cermeñozs, 1990).

Ojeda et al. (2012) observaram o melhor desenvolvimento da cultivar 'Elisa' em ambientes com microclimas que apresentaram temperaturas mais amenas, variando de 12 a $17{ }^{\circ} \mathrm{C}$, com máxima de $30^{\circ} \mathrm{C}$. Em estudos realizados na Coreia do Sul, Jeong et al. (2015), encontraram maior qualidade da cultivar 'Cheongchima' quando submetida à temperaturas diurnas de $22{ }^{\circ} \mathrm{C}$, noturnas de $12{ }^{\circ} \mathrm{C}$ e $20{ }^{\circ} \mathrm{C}$ e; umidade relativa de $65 \%$. Dessa forma, é evidente, o melhor desenvolvimento da espécie em menores temperaturas.

Em estudos realizados por Santos et al. (2009) com cultivares submetidas à altas temperaturas do ar $(20,3 \mathrm{a}$ $35,3{ }^{\circ} \mathrm{C}$ ), observaram uma perda significativa da massa seca total (MST), variando de 52,5 a 111,5 $\mathrm{g} \mathrm{planta}^{-1} \mathrm{em}$ decorrência das condições climáticas. Todavia, Zuffo et al. (2016) encontraram ótimos resultados com o cultivo de alface na mesma região estudada no presente experimento, recomendando, apesar das condições climáticas impróprias, as cultivares 'Americana Raffaela' e 'Repolhuda todo ano', possuindo ambas, potencial agrícola para a região de Bom Jesus, Piauí.

Apesar das altas temperaturas registradas na região, não foi possível identificar pendoamento precoce nas plantas cultivadas, possivelmente devido à ausência de fotoperíodo longo (Silva et al., 1999). Em contrapartida, as cultivares 'Simpson' e 'Grand Rapids' obtiveram grande alongamento do caule, redução na emissão de folhas e presença de látex nas mesmas, características essas que segundo Silva et al. (1999) antecedem a emissão do pendão floral.

As cultivares 'Simpson' e 'Grand Rapids' apresentaram um ciclo mais precoce (45 dias), quando com- parada às demais (52 dias), ambas com constante térmica (CT) de $898^{\circ}$ gd. Em relação a oferta de energia, obtevese a disponibilidade de, em média, 20,5 ${ }^{\circ} \mathrm{gd}$ por dia (Fig. 6).

As cultivares 'Bruna' e 'Palmas', como já mencionado anteriormente, apresentaram ciclo de 52 dias, com $\mathrm{CT}=1050^{\circ} \mathrm{gd}$ (Fig. 7). Durante o ciclo destas cultivares, obteve-se a disponibilidade de energia de $20,6^{\circ} \mathrm{gd}$ por dia.

Nota-se nas Figs. 6 e 7, que a maior disponibilidade de energia se dá no início do ciclo da cultura, tendo uma queda entre o final de março e início de abril. Essa situação se deu em favor da ocorrência de chuvas, pois, a nebulosidade presente na atmosfera tende a refletir e absorver a radiação solar, diminuindo assim, a sua oferta na superfície (Vianello, 2000). Registrou-se a precipitação de $14,7 \mathrm{~mm}$, durante todo o período experimental, no interior da estufa.

As fases que necessitaram de maior quantidade de energia, para todas as cultivares foram, respectivamente, aparecimento da $1^{\circ}$ folha verdadeira-transplantio e transplantio-colheita. Essas possuem maior CT, obviamente, devido estas serem fases que demandam tempo para o desenvolvimento correto da planta. Pode-se observar uma quantificação mais detalhada das necessidades de cada estádio fenológico na Tabela 2.

De acordo com a Tabela 2 pode-se perceber que as cultivares classificadas como precoces e tardias possuem, entre si, um padrão na quantidade de energia necessária para mudar de fase. Além disso, nota-se que a oferta térmica correspondente à climatologia de Bom Jesus, supriu as necessidades dos genótipos avaliados.

Os tratamentos utilizados afetaram o acúmulo térmico (constante térmica) significativamente $(p<0,01)$ segundo o teste de F (Tabela 3). Obteve-se, dessa forma,

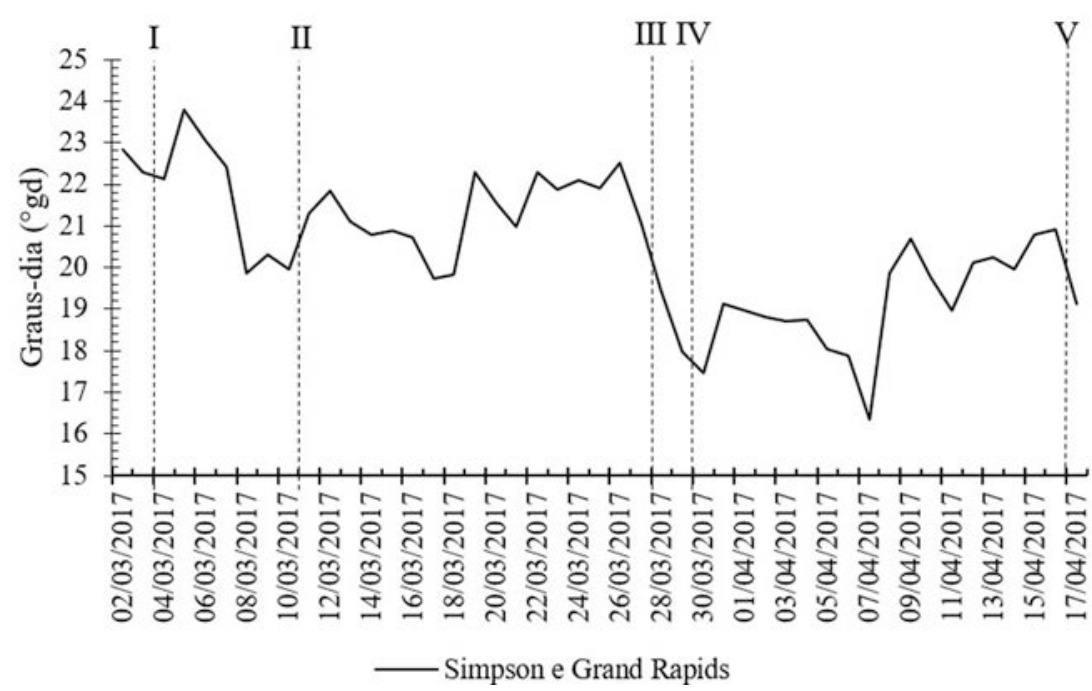

Figura 6 - Evolução da oferta de energia (graus-dia) segundo as necessidades térmicas das cultivares de alface 'Simpson' e 'Grand Rapids', no período de 02/03/2017 a 18/04/2017, na região de Bom Jesus - PI. 


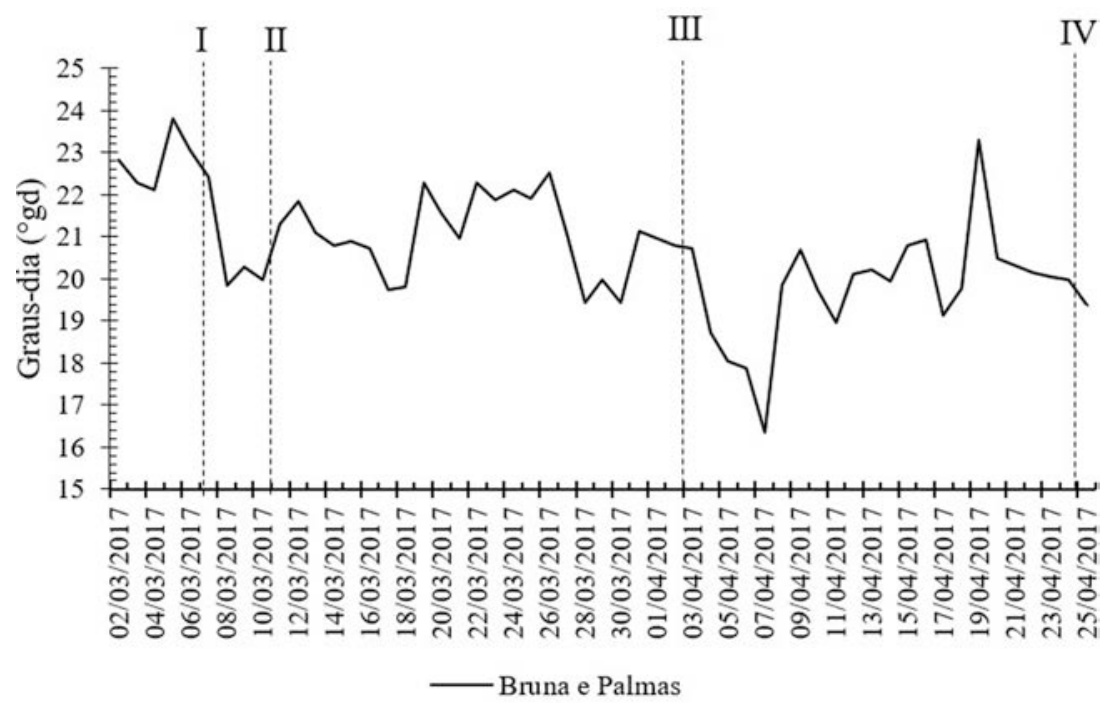

Figura 7 - Evolução da oferta de energia (graus-dia) segundo as necessidades térmicas das cultivares de alface 'Bruna' e 'Palmas', no período de 02/03/ 2017 a 25/04/2017, na região de Bom Jesus - PI.

Tabela 2 - Necessidades térmicas em graus-dia $\left({ }^{\circ} \mathrm{gd}\right)$ para os estádios fenológicos de diferentes cultivares de alface.

\begin{tabular}{lcccc}
\hline Fases & Simpson & Palmas & Bruna & Grand R. \\
\hline I-II & 67,2 & 136,5 & 136,5 & 67,2 \\
II-III & 140,7 & 81,4 & 81,4 & 140,7 \\
III-IV & 351,9 & 450,2 & 450,2 & 380,9 \\
IV-V & 338,4 & 382,4 & 382,4 & 309,4 \\
\hline
\end{tabular}

I - Semeadura; II - Emergência; III - Aparecimento da $1^{\circ}$ folha verdadeira; IV - Transplante; V - Colheita.

cultivares que possuíram maior e menor demanda térmica, com diferença estatística.

As cultivares 'Simpson' e 'Grand Rapids' (Tabela 3) apresentaram, estatisticamente, menor acúmulo térmico (898 $\mathrm{gd})$, ou seja, a quantidade de energia necessária para

Tabela 3 - Resumo da análise de variância e teste de médias (Tukey a $5 \%)$ para a capacidade térmica de diferentes cultivares de alface na climatologia de Bom Jesus, Piauí.

\begin{tabular}{lc}
\hline FV & QM \\
\hline Blocos & $15,9^{\mathrm{NS}}$ \\
Resíduo & 13,8 \\
Cultivares & $76169,1^{* *}$ \\
Bruna & $1050,7 \mathrm{a}$ \\
Palmas & $1050,25 \mathrm{a}$ \\
Simpson & $898,6 \mathrm{~b}$ \\
Grand Rapids & $898 \mathrm{~b}$ \\
$\mathrm{CV}(\%)$ & 0,38 \\
\hline NS ${ }_{\text {não significativo; **Significativo a } 1 \%(\mathrm{p}<0,01) . \text { Médias seguidas pela }}$ \\
mesma letra na coluna, não diferem estatisticamente entre si pelo teste de \\
de Tukey $(p<0,05)$.
\end{tabular}

essas atingirem o ponto de colheita é menor que as demais cultivares. Assim, é possível afirmar que a ação das altas temperaturas do ar no período analisado, disponibilizou às essas cultivares uma maior oferta de energia diária, reduzindo a duração de cada estádio fenológico e, consequentemente, o seu ciclo de vida. Além disso, tanto o genótipo quanto a própria capacidade de assimilação de energia das mesmas podem ter contribuído para o desenvolvimento precoce (Taiz e Zeiger, 2013).

Vale ressaltar que a grande quantidade de energia além de proporcionar redução do ciclo da cultura, pode também garantir que as plantas folhosas apresentem maior rigidez em suas folhas, comprometendo a comercialização (Taiz e Zeiger, 2013).

Salienta-se que não há trabalhos atuais que relacionam diretamente o acúmulo térmico com a fenologia da alface, dessa forma há carência científica sobre tal assunto. Assim, enfatiza-se a importância do presente trabalho visto que com os resultados pode-se ter um melhor manejo no cultivo da cultura.

Dentre todas as variáveis de crescimento vegetal, foi possível verificar efeito dos tratamentos $(p<0,05)$ somente para a altura de plantas (AP), número de folhas (NF), peso de massa fresca (PMF) e peso de massa seca (PMS) (Tabela 4).

Comparando-se os resultados dos parâmetros avaliados que obtiveram influência significativa das cultivares (AP, NF, PMF e PMS), observa-se que a cultivar 'Simpson' apresentou valores superiores às demais em relação à AP e NF. Pressupõem-se que a superioridade em relação à AP se deu em favor da manifestação de características prépendoamento precoce, como já mencionado anteriormente. Em contrapartida, apresentou PMF e PMS superiores, 
Tabela 4 - Resumo da análise de variância (a) e teste de médias - Tukey a $5 \%$. (b) para altura de planta (AP), diâmetro do caule (DC), número de folhas (NF), diâmetro da roseta (DR), peso de massa fresca (PMF) e peso de massa seca (PMS) de diferentes cultivares de alface cultivadas sob o regime climático de Bom Jesus, Piauí.

\begin{tabular}{lccccccc}
\hline \multirow{2}{*}{ FV } & GL & \multicolumn{6}{c}{ QM } \\
\cline { 2 - 7 } & & AP & DC & NF & DR & PMF & PMS \\
\hline Cultivares & 3 & $212,09^{* *}$ & $1,9^{\mathrm{NS}}$ & $19,5^{* *}$ & $2,05^{\mathrm{NS}}$ & $363,26^{* *}$ & $1,4^{* *}$ \\
Blocos & 9 & $10,5^{\mathrm{NS}}$ & $0,16^{\mathrm{NS}}$ & $2,04^{*}$ & $8,36^{\mathrm{NS}}$ & $24,3^{\mathrm{NS}}$ & $0,18^{\mathrm{NS}}$ \\
Resíduo & 27 & 13,69 & 0,83 & 0,89 & 6,81 & 32,4 & 0,11 \\
CV (\%) & 22,5 & 12,4 & 9,93 & 10,19 & 24,16 & 29,4 \\
\hline \hline & & & & & & \\
Cultivares & $\mathrm{AP}$ & & $\mathrm{NF}$ & $\mathrm{PMF}$ & PMS \\
\hline Simpson & $22,83 \mathrm{a}$ & $11,30 \mathrm{a}$ & $23,8 \mathrm{a}$ & $1,10 \mathrm{a}$ \\
Palmas & $15,28 \mathrm{~b}$ & $8,33 \mathrm{c}$ & $28,44 \mathrm{a}$ & $1,52 \mathrm{a}$ \\
Bruna & $11,84 \mathrm{~b}$ & $10,0 \mathrm{~b}$ & $27,0 \mathrm{a}$ & $1,37 \mathrm{a}$ \\
Grand Rapids & $15,90 \mathrm{~b}$ & $8,5 \mathrm{c}$ & $15,0 \mathrm{~b}$ & $0,67 \mathrm{~b}$ \\
\hline
\end{tabular}

não se diferindo significativamente das cultivares 'Palmas' e 'Bruna'.

A cultivar 'Grand Rapids TBR' apresentou valores inferiores em relação ao PMF e PMS apesar de ter AP e NF igual às cultivares 'Palmas' e 'Bruna'. Zuffo et al. (2016) encontrou resultados similares para as mesmas variáveis em estudo realizados com a cultivar 'Grand Rapids TBR', na região de Bom Jesus - PI.

Os melhores resultados foram obtidos pelas cultivares 'Palmas' e 'Bruna'. A cultivar 'Palmas' apresentou os maiores PMF e PMS. Essa resposta de ambas pode estar relacionada com o melhoramento genético da cultura, que tornou alguns cultivares mais tolerantes a altas temperaturas, conforme documentado por Feltrim et al. (2005).

Dessa forma, apesar de terem uma maior necessidade térmica ( $\left.1050^{\circ} \mathrm{gd}\right)$, as cultivares 'Palmas' e 'Bruna' apresentaram melhor resposta em seu crescimento e desenvolvimento nas condições climáticas de Bom Jesus - PI.

Sabe-se que a temperatura do ar é um elemento climático que sofre total influência da variação da quantidade e qualidade da radiação solar incidente na atmosfera (Vianello, 2000). Dessa forma, tem-se que esse elemento é um agente condicionante no crescimento vegetal (Kitao et al., 2000) e quanto maior seu valor, maior a radiação incidente $\mathrm{e}$, maior a oferta de energia para os seres fotossintetizantes produzirem fotoassimilados. Quando relacionou-se as variáveis fitotécnicas e meteorológicas, encontrou-se apenas relações significativas $(p<0,05)$ para AP, NF e DR das cultivares 'Simpson', 'Palmas' e 'Grand Rapids TBR' quando comparadas com a temperatura média do ar $\left({ }^{\circ} \mathrm{C}\right)$, conforme exposto na Fig. 7.

Assim, enfatiza-se na Fig. 8 o aumento na disponibilidade de energia proporcionado pelo aumento da temperatura do ar e seu efeito positivo nos parâmetros
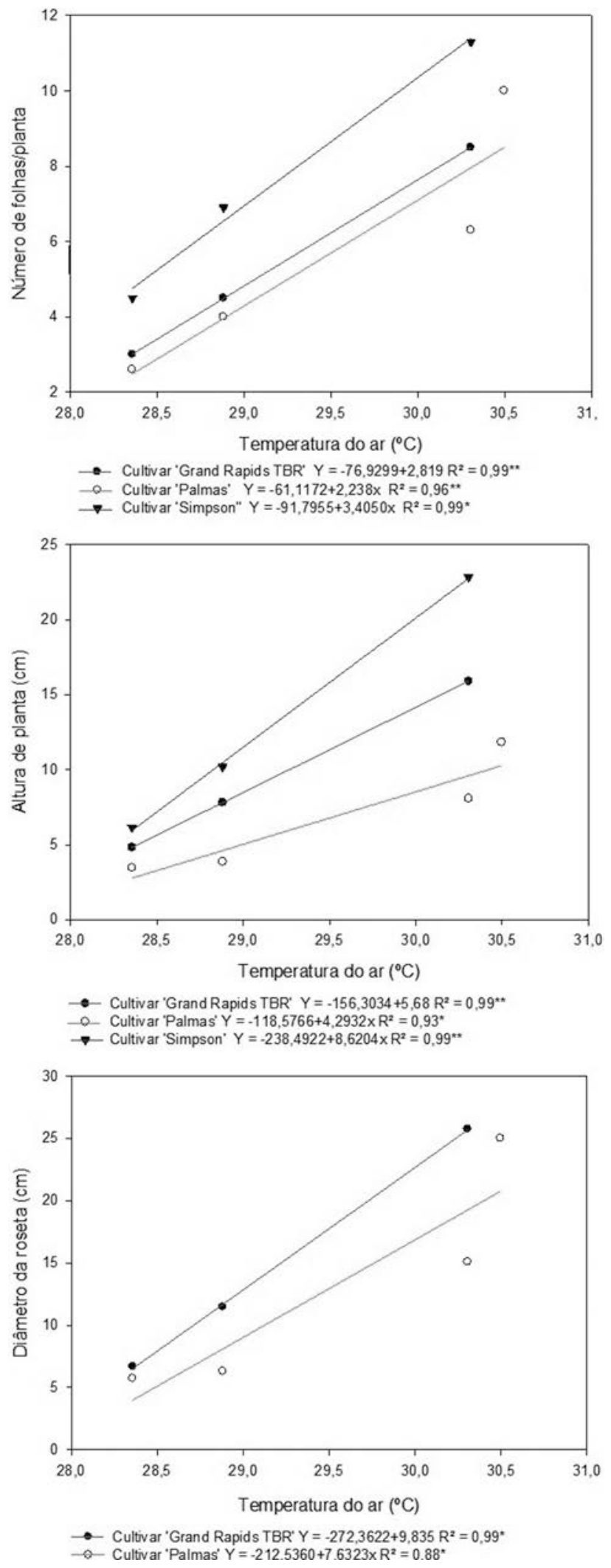

Figura 8 - Análise de regressão entre variáveis fitotécnicas e temperatura média do ar para as cultivares de alface 'Simpson', 'Palmas' e 'Grand Rapids TBR' cultivadas em ambiente protegido sob o regime climático de Bom Jesus, Piauí. 
avaliados, em favor do aumento da taxa fotossintética com consequente maior produção de fotoassimilados e desenvolvimento vegetal (Taiz e Zeiger, 2013).

Vale ressaltar que até a temperatura média avaliada, não foi possível verificar efeito negativo das altas temperaturas no crescimento das cultivares, por meio da análise de regressão, no entanto, acredita-se que ao se distanciar mais da temperatura tolerável pela cultura $\left(30{ }^{\circ} \mathrm{C}\right)$ haverá a manifestação de tais efeitos.

A cultivar 'Bruna' não apresentou relação direta com nenhuma variável meteorológica. Assim, é perceptível que os elementos climáticos, apesar de terem suma importância no crescimento e desenvolvimento vegetal, não possuem influência direta em todas as cultivares e parâmetros fitotécnicos da Alface, quando cultivado em condições protegidas em Bom Jesus, PI. Portanto, evidenciase que a espécie pode sofrer influência não só de condições climáticas, mas também de sua condição hormonal, nutricional, hídrica e do solo (Taiz e Zeiger, 2013).

Dentre as cultivares avaliadas, as cultivares 'Palmas' e 'Bruna' obtiveram comportamento e morfologia adequados em relação às altas temperaturas regionais. Logo, é possível afirmar, com base no regime climático observado na cidade de Bom Jesus, nas temperaturas basais e toleráveis das cultivares e em seus crescimentos e desenvolvimentos (diâmetro da roseta maior que $25 \mathrm{~cm}$ ) que as cultivares 'Palmas' e 'Bruna' possuem potencial produtivo para a região, quando cultivada em ambiente protegido, no entanto, recomenda-se a utilização de microaspersão ou estufas com janelas laterais abertas para que a temperatura seja atenuada e haja melhor produção de biomassa.

Assim, faz-se necessária a realização de mais estudos que permitam relacionar de forma mais concisa os elementos climáticos ao crescimento e desenvolvimento do da Alface, especialmente ao tipo 'Palmas' e 'Bruna', uma vez que há carência de trabalhos que permitam essa associação direta na região do Cerrado piauiense. Por este motivo, torna-se imprescindível um esforço maior no conhecimento dessas relações, tendo em vista o eminente efeito das mudanças climáticas globais na produção vegetal.

\section{Conclusões}

1. As cultivares 'Simpson' e 'Grand Rapids' apresentarem menor constante térmica (CT $=898^{\circ} \mathrm{gd}$ ) quando comparada à 'Palmas' e 'Bruna' $\left(\mathrm{CT}=1050^{\circ} \mathrm{gd}\right)$.

2. Os melhores resultados de crescimento em favor das condições climáticas foram apresentados pelas cultivares 'Palmas' e 'Bruna'.

3. A temperatura do ar é o elemento climático que possui o maior efeito sobre o desenvolvimento da Alface.

4. As cultivares 'Palmas' e 'Bruna' possuem potencial agrícola para a região, quando cultivadas em ambiente protegido adequado (atenuação da temperatura).

\section{Referências}

BRUNINI, O.; LISBÃO, R.S.; BERNAR-DI, J.B.; FORNASIER, J.B.; PEDRO JÚNIOR, M.J. Temperatura-base para alface cultivar "White Boston", em um sistema de unidades térmicas. Bragantia, v. 35, n. 1, p. 213-219, 1976.

CARVALHO FILHO, J.L.S.; GOMES, L.A.A.; MALUF, W.R. Tolerância ao florescimento precoce e características comerciais de progênies F4 de alface do cruzamento Regina 71 x Salinas 88. Acta Scientiarum. Agronomy, v. 31, n. 1, 2009.

CERMEÑOZS. Estufas, instalações e manejo. Lisboa: Litexa Editora, 355 p. 1990.

DUARTE, R.L.R.; SILVA, P.H.S.; RIBEIRO, V.Q. Avaliação de cultivares de alface nos períodos chuvosos e secos em Terezina-PI. Horticultura Brasileira, v. 10, n. 2, p. 106-108, 1992.

FELTRIM, A.L.; FILHO, A.B.C.; BRANCO, R.B.; BARBOSA, J.C.; SALATIEL, L.T. Produção de alface americana em solo e em hidroponia, no inverno e verão, em Jaboticabal, SP erão, em Jaboticabal, SP. Revista Brasileira de Engenharia Agrícola e Ambiental, v. 9, n. 4, p. 505-509, 2005.

FILGUEIRA, F.A.R. Novo manual de olericultura: agrotecnologia moderna na produção e comercialização de hortaliças. 2. ed. rev. ampl. Viçosa: UFV, 421 p, 2008.

INMET. Normal climatológica. Disponível em: http://www. inmet.gov.br/portal/index.php?r=clima/normaisClimatologi cas. Acesso em: junho de 2017.

JEONG, S.W.; KIM, G.S.; LEE, W.S.; KIM, Y.H.; KANG, N.J. et al. The effects of different night-time temperatures and cultivation durations on the polyphenolic contents of lettuce: Application of principal component analysis. Journal of advanced research, v. 6, n. 3, p. 493-499, 2015.

KITAO, M.; LEI, T.T.; KOIKE, T.; TOBITA, H.; MARUYAMA, Y.; MATSUMOTO, Y.; ANG, L.H. Temperature response and photoinhibition investigated by chlorophyll fluorescence measurements for four distinct species of dipterocarp trees. Physiologia Plantarum, v. 109, n. 3, p. 284-290, 2000.

OJEDA, A.D.; LIGARRETO, G.A.; MARTÍNEZ, O. Effects of environmental factors on the morphometric characteristics of cultivated lettuce (Lactuca sativa L.). Agronomía Colombiana, v. 30, n. 3, p. 351-358, 2012.

PEREIRA, A.R; ANGELOCCI, L.R; SENTELHAS, P.C Agrometeorologia: fundamentos e aplicações práticas Guaíba: Agropecuária, 478 p, 2002.

R Core Team (2014). R: A language and environment for statistical computing. R Foundation for Statistical Computing, Vienna, Austria, 2014. http://www.R-project.org/.

SANTOS, C.L; DOS SANTOS, C.L.; JUNIOR, S.S.; DE LALLA, J.G.; DE THEODORO, V. C.A.; NESPOLI, A. Desempenho de cultivares de alface tipo crespa sob altas temperaturas em Cáceres-MT. Agrarian, v. 2, n. 3, p. 8798, 2009.

SALA, F.C.; COSTA, C.P. Retrospectiva e tendência da alfacicultura brasileira. Horticultura Brasileira, Vitória da Conquista, v. 30, n. 2, p. 187-194, 2012.

SCHAFER, V.F. Produção de alface na região mesoclimática de Santa Maria, RS. Dissertação (Mestrado) - Escola Superior de Agricultura “Luiz de Queiroz”, 2009. 
Sigma Plot For windows, version 10.0 Systat Software, 2008.

SILVA, E.C.; LEAL, N.R.; MALUF, W.R. Avaliação de cultivares de alface sob altas temperaturas em cultivo protegido em três épocas de plantio na região norte-fluminense. Ciência e Agrotecnologia, v. 23, p. 491-499, 1999.

SILVA, V.D.; BEZERRA NETO, F.; NEGREIROS, M.D.; PEDROSA, J.F. Comportamento de cultivares de alface em diferentes espaçamentos sob temperatura e luminosidade elevadas. Horticultura Brasileira, v. 18, n. 3, p. 183-187, 2000.

SOUSA, C.S.; BONETTI, A.M.; GOULART FILHO, L.R.; MACHADO, J.R.A.; LONDE, L. N.; BAFFI, M.A.; RAMOS, R.G.; VIEIRA, C.U.; KERR, W.E. Divergência genética entre genótipos de alface por meio de marcadores AFLP. Bragantia, v. 66, n. 1, p. 11-16, 2007.

SUINAGA, F.A.; BOITEUX, L.S.; CABRAL, C.S.; RODRIGUES, C.D.S. Métodos de avaliação do florescimento precoce e identificação de fontes de tolerância ao calor em cultivares de alface do grupo varietal. Embrapa Hortaliças-Comunicado Técnico (INFOTECA-E), 2013.

TAIZ, L.; ZEIGER, E. Fisiologia vegetal. 5.ed. Porto Alegre: Artmed, 91 8p., 2013.

VARGAS, P.F.; DUARTE, L.S.; ZECCHINI, A.C. Hortifruti: Pendoamento da Alface. 2015. Disponível em: http:// www.revistacampoenegocios.com.br/pendoamento-preco ce-da-alface-e-agora/. Acesso em abril de 2016.

VIANELLO, R. L. Meteorologia básica e aplicações. Viçosa: UFV, 2000.

ZUFFO, A.M.; ZUFFO JÚNIOR, J.M.; SILVA, L.M.A.; SILVA, R.L.; DE MENEZES, K.O. Análise de crescimento em cultivares de alface nas condições do sul do Piauí. Revista Ceres, v. 63, n. 2, p. 113-120, 2016.

License information: This is an open-access article distributed under the terms of the Creative Commons Attribution License (type CC-BY), which permits unrestricted use, distribution and reproduction in any medium, provided the original article is properly cited. 